\title{
On the Structural Behaviour to Penetration of Striking Bow under Collision Incidents between Two Ships
}

\author{
A. R. Prabowo ${ }^{1, *}$, H. Nubli ${ }^{2}$ and J. M. Sohn ${ }^{3}$ \\ ${ }^{1}$ Department of Mechanical Engineering, Universitas Sebelas Maret \\ Surakarta 57126, Central Java, Indonesia \\ ${ }^{2}$ Interdisciplinary Program of Marine Convergence Design, Pukyong National \\ University, Busan 48513, South Korea \\ ${ }^{3}$ Department of Naval Architecture and Marine Systems Engineering, Pukyong National \\ University, Busan 48513, South Korea \\ Email: aditya@ft.uns.ac.id
}

\begin{abstract}
This work addressed the evaluation of collision angle and indenter on the behaviour of target object. A series of collision scenarios based on the mentioned parameters were calculated using finite element method. In the analysis process, several striking ships of different sizes relative to the struck ship are deployed as the collision angles ranging from $0^{\circ}$ to $180^{\circ}$ are taken into consideration. The results relative to the angles show that the perpendicular collision or a collision angle of $90^{\circ}$ produces the lowest level of the internal energy in the side collision category by comparison with oblique collisions in the range of collision angles from $30^{\circ}$ to $150^{\circ}$. The internal energy is found to be satisfactory when it is compared with the extent of the damage on the outer shell, which is also matched with the predicted energy behaviour from energy formulae.
\end{abstract}

Keywords: ship collision; collision angle; finite element analysis; structural behaviour; extent of damage.

\section{INTRODUCTION}

A sign of advanced development in terms of human relationships can be assessed by the characteristic of the industrial trading activities. The domestic part of trading heavily influences the rapid improvement of the road - railway safety and traffic regulations against accidental events. On the other hand, international trading is conducted through an export-import using water transportation mode. Shipping for export-import transportation and distribution has been performed since the concept of shipbuilding was introduced and implemented as one of the most important pillars in human-to-human economic transactions. Throughout this journey, maritime rules for safety instruments and ship structure itself have undergone continuous development to achieve satisfaction in terms of cost and safety. In sailing activities, the ship as a transportation mode experienced various loads, for instance, the live load of crew and passengers, distributed loads of cargo and machinery, the hydrostatic load of ship draught, and the hydrodynamic load of the sea wave. In addition to these, serious attention is also addressed to other forms of load, such as the impact as an accidental load. The magnitude of this load can be both small and large. The hull structural members have the possibility of experiencing this accidental load in the form of grounding (Nguyen et al. [1]; Prabowo et al. [2-4]) and collision (Ståhlberg et al. [5] Bae et al. [6] Prabowo et al. [7-8]), which may lead to a 
chain of disasters such as structural failure, ship sinking, and environmental pollution. Due to its characterization as an accident, the possibility of the occurrence of a collision on a marine structure such as a ship is affected by numerous parameters, e.g., human factors, weather and natural behaviour, and instrumental failure. The possibilities may be limitless, and continuous study in this area is needed. The influence of material and design as the internal parameters of the involved objects on structural response has been observed, leading the present work to evaluate structural behaviour due to the external factor that is also important in collision phenomena.

In this work, ship collision is studied by numerical simulation. The ships involved are taken as initial parameters in defining the dynamic scenario. Preparation for the model and the role in a collision is described. The collision angle and the designated target location are determined, together with the configuration of the finite element method to complete the scenario. The method applied in this work will be verified with a convergence study based on an impact experiment to ensure the reliability of the results. The structural behaviour of a double-side shell (DSS) subjected to defined parameters is discussed, and the final remarks are summarised in the conclusion section.

\section{LITERATURE REVIEW}

\section{Development on Impact Analyses}

Chain reactions from collision and grounding such as disastrous oil spills from a struck ship have become one of the major problems in relation to conservation of maritime environment. The analysis methods of collision and grounding have been developed to predict structural responses which can be used to design mitigation and evacuation plans. Development is conducted in several ways, for instance through calculation instruments. The calculation method is started with the empirical method. Survey and real experiment data are used to make empirical formulae that can be used to calculate the prediction of the internal energy in a collision process. A series of empirical was introduced by Minorsky [9], Woisin [10], and Zhang [11] consecutively which consisted of observation and review on full-scale experiments, analytical theory, limit analysis and finite element (FE) simulation. Second is the limit analysis or simplified method. It has been proven that this method is valuable for estimating the collapse load of a structure subject to extreme loads. The third is the direct measurement or experimental method. In the time period 1962 to 1976, investigators in Italy, Germany and Japan conducted a series of model tests. Even though the results of this method are very accurate, the cost level is very high. Furthermore, the preparation and experiment instruments require additional cost in both money and time.

As the rapid development in computational instruments, the finite element method appears as a dependable method to analyse collision and grounding phenomenon. Because this method works virtually, the cost on material samples can be reduced, and also it is useful to analyse collision and grounding accidents which involve high nonlinearity, such as colliding surfaces contact, friction and rupture. Deployment of the explicit methodology is recommended to assess the mentioned phenomenon. The required calculation efforts are less than the commonly used implicit methods. The convergence of calculations is much easier to realize. Explicit methodologies based computer codes include ABAQUS /Explicit, DYTRAN, and LS-DYNA, and implicit methodologies based codes include ABAQUS/Standard, ANSYS, and NASTRAN [12]. Result reliability of FE simulation in collision and grounding analysis also depends on its 
verification, the study must be based on the data of the actual accidents, or the physical experiments and finite element analysis [13-14] to obtain good accuracy and practicality.

\section{Reference in Failure Phenomena}

It is well known from numerous practical experiences and theoretical investigations that failure depends on the stress states which can result under complicated loads in the structures. In order to obtain practical failure strain definitions in consideration of many parameters, e.g. element size, stress state and manufacture influence many full-scale thickness measurements on prototype-damaged structure components such as shell plating and stiffeners have been conducted and the uniform strain, necking as well as necking length have been determined [15]. On micro-structural observation, a fracture is initiated on the small impurities inside the material. These impurities nucleate and create material voids, which will grow and coalesce as the deformation continues to take place on the material. Fractures begin on a macro-structural observation when the ligament between the voids have thinned down to a certain level [16]. In structural analysis, especially where failure is involved, there are several fracture models that can be used to simulate rupture. Most of them use damage criteria to describe either shear damage or void growth. However, this method is too complex for practical use. Therefore, the RTCL criterion was introduced and verified by Törnqvist [17] at the Technical University of Denmark. This model combines the Rice-Tracey void growth criterion [18] and the Cockroft-Latham damage model [19].

\section{Collision Topology and Scenario}

Ship collision is a very complicated process in which the behaviour of the striking and struck objects will be different since the objects have different properties of material and structure. Large energy dissipation, fluctuation contact force, crushing of deformable components, and rupture of involved materials occur during the interaction of the two objects. The consequences may be remarkable, and this process is included in the nonlinear class. As stated in a previous section, the process of a collision event is very complex, and countless possibilities can be obtained from certain event predictions. Therefore, in the collision analysis, it is important to define and determine the situation that will be implemented in the simulation as either a boundary condition or a constraint function. The scenarios in ship collision are simplified by the coordinate system on ship collision by Zhang [20] which shows that the angle of collision $(\beta)$ has a vital influence in a side collision event. The angle of collision here is defined as the angle formed between two ships based on their position and direction.

Due to its importance, the angle is taken as the main observation subject in this work. The scenario in this research will be composed based on the collision position or angle between the two ships. The angle of collision $(\beta)$ is determined as the control variable in which seven different angles in the range of $0^{\circ}$ to $180^{\circ}$ are deployed to observe the behaviour of the structure in the collision process. The $0^{\circ}$ is defined when the striking ship comes to the struck ship from the aft end direction, while the $180^{\circ}$ is the situation where the striking ship approaches from the direction opposite to the struck ship. A review of the results will suggest which angle produces a side collision and a sliding phenomenon. A side collision in this research is defined as the collision where the striking ship has clearly penetrated the struck ship. In this case, part of or the whole body of the striking ship successfully penetrates to the inside of the struck ship and leaves damage 
such as tearing or displacement. However, the sliding phenomenon is a situation where parts of the striking and struck ships contact each other, but no significant or direct penetration occurs. Friction mostly occurs in this phenomenon, with minor deformation and plastic tension damage occurring on the deformable structure.

\section{SCENARIO PREPARATION AND CONFIGURATION OF VIRTUAL EXPERIMENT}

\section{Verification of the Numerical Configuration}

This verification considers the conducted impact experiment of Alsos and Amdahl [21] at NTNU, which addresses hull damage in ships subjected to impact load. Even though this work is initially addressed to study the structural failure mechanism of the ship against stranding, the preparation and methodology of this experiment are considered to be matched with the penetration phenomenon in ship collisions. Application of a stiffened plate to represent the ship structure in this experiment is similar to the structural arrangement on the side hull where the side shell is strengthened by frame and stringer. The result of the numerical simulation in this study will be compared with the penetration experiment and the recent work of AbuBakar and Dow [22].

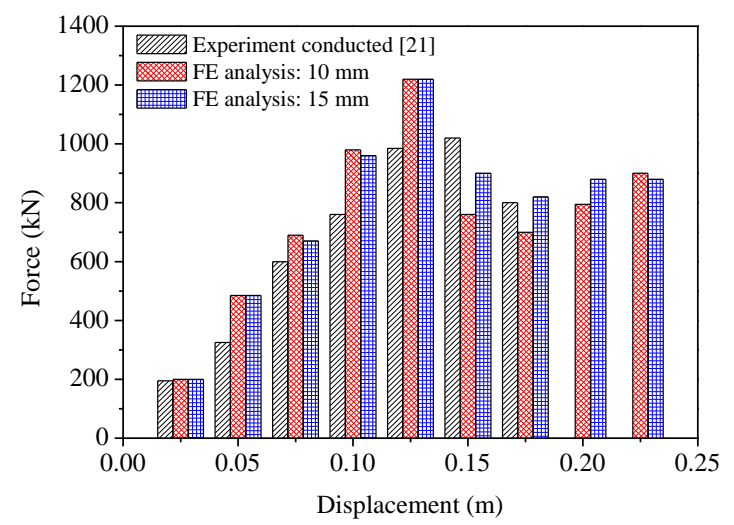

(a)

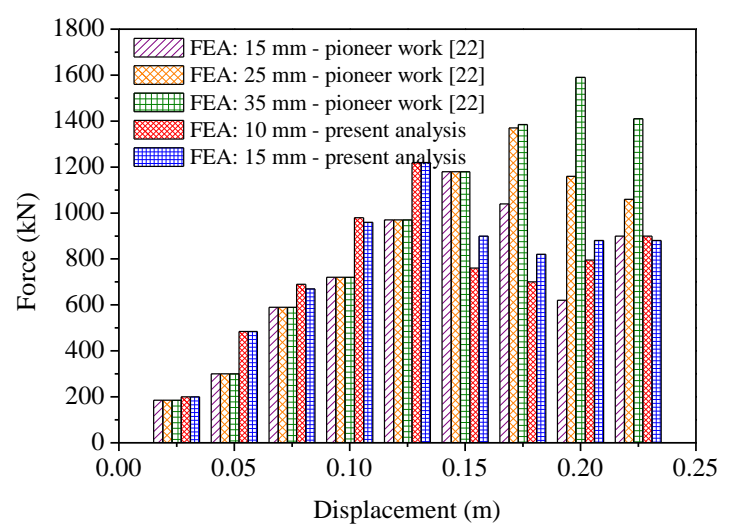

(b)

Figure 1. Results of verification with laboratory experiment: (a) comparison of benchmark simulation between the experiment and numerical simulation with present configuration, and (b) behaviour of force during the impact process. Comparison takes work of AbuBakar and Dow [22] as verification of the present method.

In the present work, two simulations with different meshing sizes are conducted. The typical element size for the whole simulated structure is approximately $10 \times 10 \mathrm{~mm}$ and $15 \times 15 \mathrm{~mm}$. The total elements for each simulation are obtained as 71725 and 32272, consecutively. Contact is modelled between the indenter and the structural members of the stiffened plates. Plastic kinematic material is applied on the stiffened plate as the target structure with density $\rho=7850 \mathrm{~kg} \cdot \mathrm{mm}^{-3}$, Young's modulus $E=210 \mathrm{GPa}$, Poisson's ratio $v=0.3$, and yield strength $\sigma_{Y}=260 \mathrm{MPa}$. Strain rate effects are included in the material model, namely, Cowper-Symonds parameters $C_{c s}=4000 \mathrm{~s}^{-1}$ and $q=5.0$. The target structure is modelled with a shell element with fully integrated Belytschko-Tsay with element formulation number (EF no.) 12, which uses a 2 x 2 quadrature in the shell plane. Even though simulation time is slower (approximately 2.5 times slower than the ordinary 
Belytschko-Tsay $($ EF no. $=1)$ ), this element type is useful in overcoming hourglass modes and shear locking phenomenon.

The force-displacement graph determined from finite element analysis of the impact experiment is presented in two figures. The comparison with the experiment is shown in Figure 1(a) which good correlation is achieved when the contact force of the simulation is found to be higher on certain points. Further verification (Figure 1(b)) is presented by AbuBakar and Dow [22], who also took the penetration experiment of Alsos and Amdahl [21] as a reference in their work. The conclusion of this comparison indicates that the previous work of AbuBakar and Dow produced the highest result in terms of contact force compared to the experiment and the present simulation. However, a similar tendency of experiment and numerical analysis from this work with the results of AbuBakar and Dow as well as Alsos and Amdahl is successfully verified.

\section{Finite Element Procedure}

The present analysis is addressed as a continuation of previous work of Prabowo et al. [23], which already considered a location in determining a series of collision scenarios that used the same struck and striking ships for each case. In the present calculation, three ships are used in the experiment and will be classified as the involved ships. The first ship is the Ro-Ro passenger ship, which will be denoted as the struck ship.

Table 1. Dimensions of the selected striking ships for collision analysis.

\begin{tabular}{lccc}
\hline Component & Striking 1 & Striking 2 & Striking 3 \\
\hline Length over all $(\mathrm{m})$ & 85.92 & 144.5 & 67.5 \\
Breadth moulded $(\mathrm{m})$ & 15 & 19.8 & 12.8 \\
Depth $(\mathrm{m})$ & 10.4 & 10.2 & 3.9 \\
Draught $(\mathrm{m})$ & 4.3 & 5.6 & 3 \\
\hline
\end{tabular}

Table 2. Dimensions and configuration of the struck ship.

\begin{tabular}{lc}
\hline Component & Dimension \\
\hline Length over all $(\mathrm{m})$ & 85.92 \\
Breadth moulded $(\mathrm{m})$ & 15 \\
Depth $(\mathrm{m})$ & 10.4 \\
Draught $(\mathrm{m})$ & 4.3 \\
\hline Web frame-1 to target point ${ }^{* *}$ & 4.8 \\
Distance (m) & 10 \\
Thickness of side plating (mm) & \\
\hline Web frame-3 to target point & 2.4 \\
Distance (m) & 10 \\
Thickness of side plating (mm) & \\
\hline Web frame-4 to target point & 4.8 \\
Distance (m) & 10 \\
Thickness of side plating (mm)
\end{tabular}

${ }^{* *}$ referring to web frame notation in Figure 2.

This ship is struck by other ships, including a similar ship, a cargo reefer, and a passenger vessel. These striking ships will be denoted as striking 1, striking 2, and striking 
3 , respectively. As introduced in the previous section regarding structure type, more detail implementation is presented in this part. The deformable structure is applied on the struck ship as the target structure, while the striking ship is given a rigid body. To observe the contribution of the structural type on the side hull response of the struck ship, striking 1 is also characterized by deformable characteristics and is denoted as striking $1^{*}$. Therefore, in this work, there is one struck ship and four striking ships, and the principal data and configuration of these ships are presented in Tables 1 and 2 for striking and struck ships, respectively. The illustration for frame numbering on the struck ship is given in Figure 2. Based on this illustration, the location of the target points is determined at the fore-end region, on the web frame number 2 according to frame numbering.

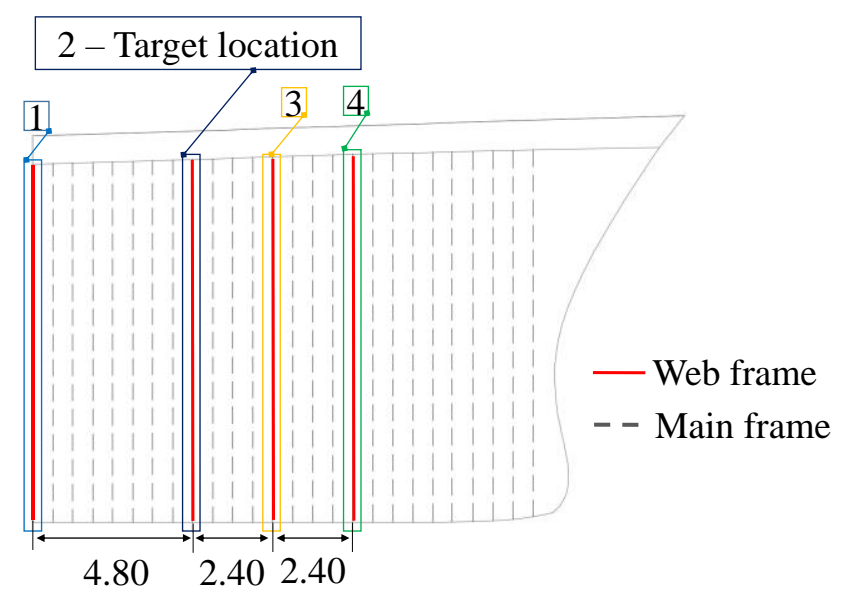

Figure 2. Target location in the longitudinal direction. Web frame number two is the designated target with the difference of this frame to other web frame is in length (m).

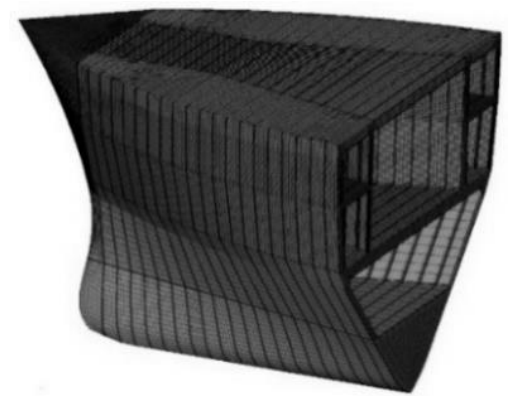

(a)

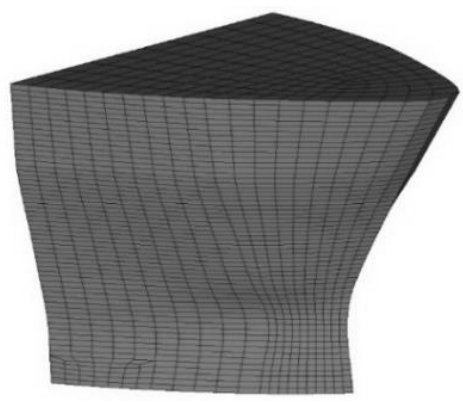

(b)

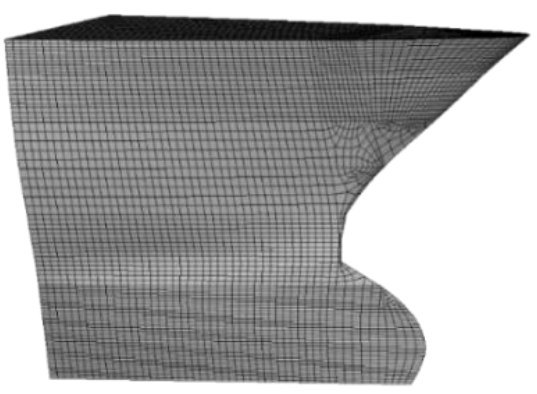

(c)

Figure 3. The striking ships: (a) similar ship; (b) cargo reefer, and (c) passenger vessel. 
Three striking ships that are shown in Figure 3 were applied in two different locations according to their sizes. Striking 3, which is smaller than the struck ship, cannot reach the same location as the other striking ships. Two locations with different elevations in the vertical direction are designated the upper and lower locations, as presented later in Figure 4. The target point on the upper location was contact with striking 1,2, and $1^{*}$ in the collision, while striking 3, which has a smaller size than the struck ship, impacted the target on the lower location. Discussion of structural response at a different location based on the reach of the striking ships under side collision is also presented in this paper.

\section{Structural Arrangement and FE Setting}

Calculation and analysis for the defined scenario are performed using the explicit FE codes ANSYS LS-DYNA [24]. In this virtual experiment, models of the involved ships are built based on structural characteristics of the fore-end region. The structural area on the deformable structure of the struck ship is taken as the main concern to obtain satisfaction in the result, especially the deformation pattern. The overall structure is divided into three main areas: core, transition, and outer, classified based on mesh size (Figure 4). The core area is the location of the smallest mesh size. In this area, a large deformation is expected to occur and in that case, very small mesh size is needed to obtain realistic deformation shapes and patterns. In addition to the core area, there is the location of the transition area. In this zone, the size of the mesh is slightly larger than the core area and not at any significant level. The other target point is placed in this area. The farthest area from the core is the outer area. The mesh size in this area is significantly larger than those in the other areas. One mesh element size is equal to 2-5 mesh element sizes from the core and transition areas. In this area, damage and deformation are predicted not to occur after the collision. The mesh size rules in this work are adopted from the convergence test between the mesh size and fracture criteria of Alsos and Amdahl [21].

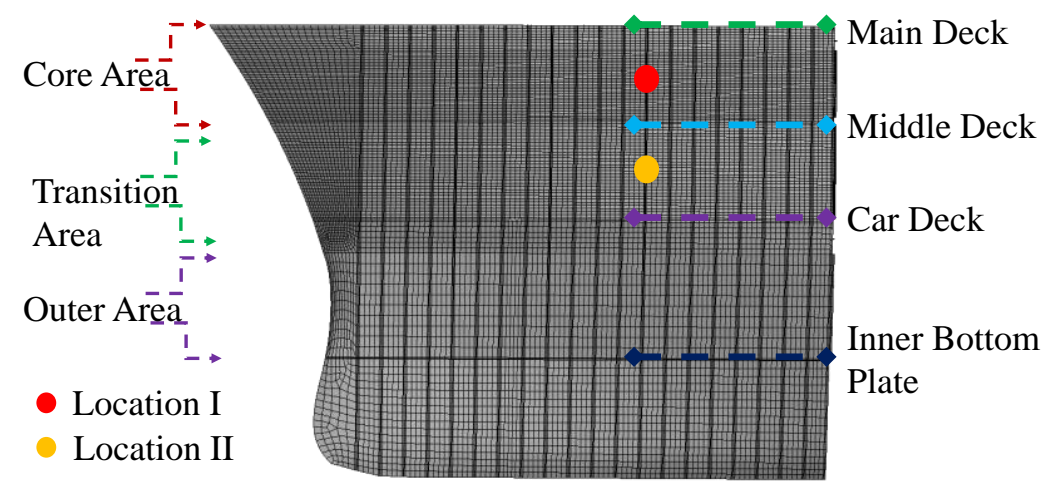

Figure 4. The bullets highlight the location of the target points in the vertical direction. Three denoted areas represent meshing size which is ordered from the Core Area; the smallest size is applied in this area.

In terms of material characteristics, the plastic-kinematics material model [24] with medium-carbon-class steel is embedded in the ship models. The mechanical properties of this material are presented in Table 3, while for element formulation for the numerical model, the Belytschko-Tsay element is implemented into the struck and striking ships. The selection of element type had been performed in previous work of Bae et al. [26] who found that this element formulation type was effective in analysing impact 
phenomena. Contact is accounted for by the general automatic contact options found in the user guide [24]. In addition to the shape and size of the striking ships, friction properties are also considered to affect structural response during contact between the striking bow and the side hull of the struck ship. This work implements the friction coefficient between mild steels with a value of 0.74 for static friction and 0.57 for dynamic friction.

Table 3. Mechanical properties of the ship material [25].

\begin{tabular}{cccc}
\hline Density $\left(\mathrm{kg} \cdot \mathrm{mm}^{-3}\right)$ & Elastic modulus $(\mathrm{Pa})$ & Poisson's ratio (-) & Yield stress $(\mathrm{Pa})$ \\
\hline 7850 & $2.10 \times 10^{11}$ & 0.3 & $4.40 \times 10^{8}$ \\
\hline
\end{tabular}

The displacement on the struck ship is set to be fixed at the centreline. The fixation is applied for all transverse frames at the end of the model of the struck ship. At the end of the shell plating, axial displacements are restrained. These constraints are applied to the struck ship as this work is intended to observe structural behaviour in the worst case according to Minorsky [9]. Collision analysis models are first developed for analysing the design of ships transporting nuclear materials. The crashworthiness of these ships under the worst-case conditions is the primary concern. The totally inelastic right-angle collision with the struck ship at rest is considered the worst case. Hence, most of the currently available models consider only right-angle collisions and assume that the kinetic energy parallel to the centreline of the struck ship is negligible. The most popular of these approaches is the one proposed by Minorsky, which states that in a collision, the rotations of the struck and striking ships are small and can be neglected. Based on this approach, Minorsky's assumption is applied to the present work to define constraints on the struck ship. In collision process, the striking ships will be implemented at a constant velocity of 12 knots or $6.17 \mathrm{~m} / \mathrm{s}$ to move into the designated target points, which structural response of the struck ship is evaluated later.

\section{RESULTS AND DISCUSSION}

Results of the numerical calculation are presented in this section. The structural responses of the struck ship when it is subjected to collision with the striking ships are evaluated and discussed. The focus is on the behaviour of absorbed strain energy, which is presented as the internal energy. In a later section, the extent of the damage to the struck ship as the target object is presented, and the resulting tendency is discussed.

\section{Internal Energy}

After the collision events that are subjected to collision angles and different striking ships as indenters, the reactions on the structure of the struck ship are presented. The discussion in this sub-section is addressed to evaluate internal energy occurring in the collision processes. As presented in Figure 5, the energy produces a tendency that it reduces as the collision angle is approaching perpendicular collision $\left(\beta=90^{\circ}\right)$, and rises again after passing this point. The internal energy of the oblique scenarios with an angle of $30^{\circ}$ and $150^{\circ}$ indicates that a significant difference from the perpendicular collision occurs. This result appears to be influenced by the phenomenon that is proposed in this work to be called earlier contact. This situation can only occur in an oblique collision, and at a certain 
angle, the absorbed strain or internal energy of ship collision is found to be remarkably higher than in the perpendicular collision.

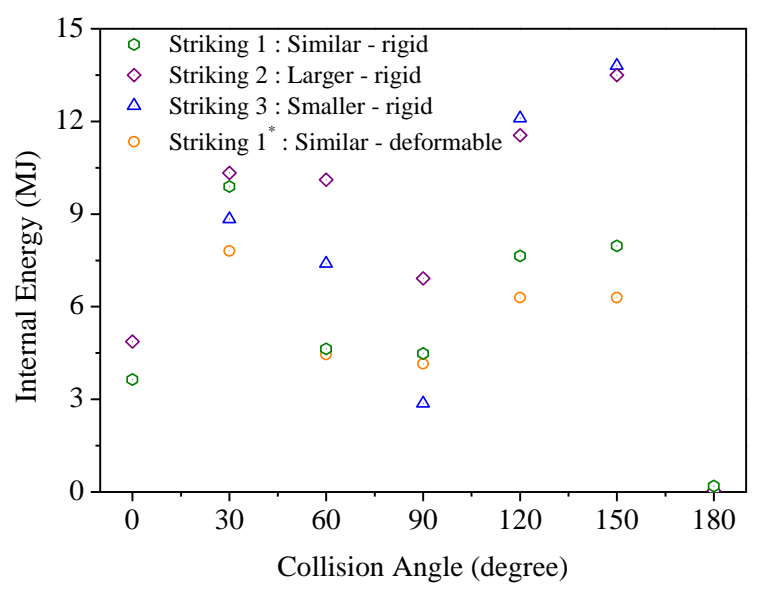

Figure 5. Magnitude of the internal energy for the proposed cases in present work.

In this scenario, for instance, two ships will collide with each other in a side collision with an initial distance before contact. The target points are determined: one on the tip of the striking ship, and one on the side hull of the struck ship. In the perpendicular collision, especially involving the striking ship with a sharp bow, both of the points can directly contact during collision without other parts on the striking and struck ships contacting each other, or it can be written more simply that the first contact between the two ships is at the designated points. However, this concept is not valid for an oblique collision, which in the collision process, especially in range of $30^{\circ}-60^{\circ}$ and $120^{\circ}-150^{\circ}$ based on the results of the present work, the side part of the striking ship contacts the other part of the side hull from the struck ship before the target points on both ships collide with each other. An illustration of this phenomenon is presented in Figure 6, which describes the situation in oblique and perpendicular collisions. The earlier the ships contact each other, the farther the distance between the real target points will occur. If this discussion is expanded into this detail, for the same proposed displacement distance of the striking ship, the oblique collision will produce a higher energy magnitude than the perpendicular scenario as the deformation process has been started earlier.

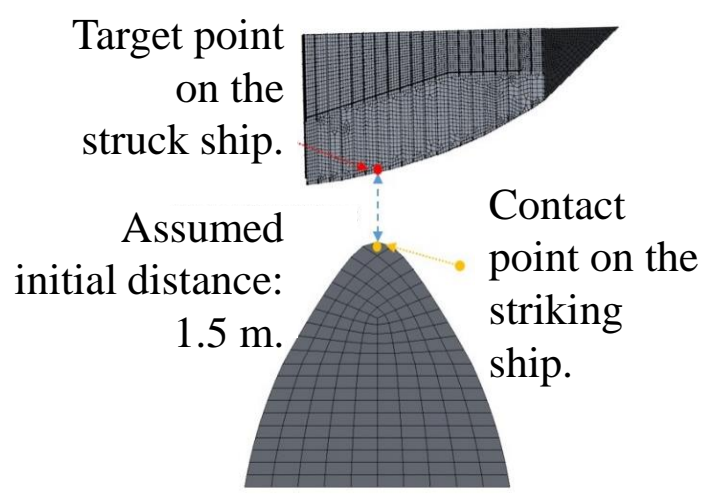

(a)

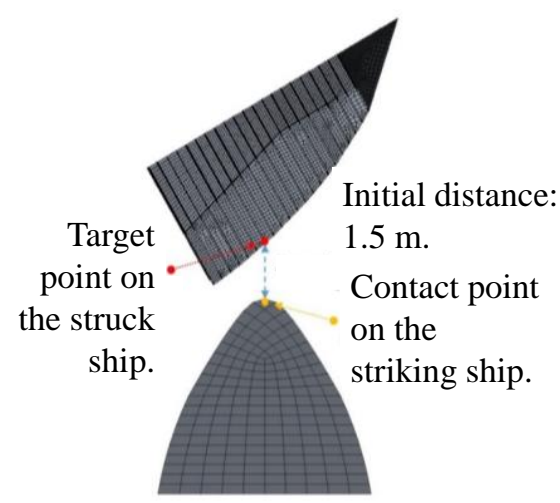

(b) 


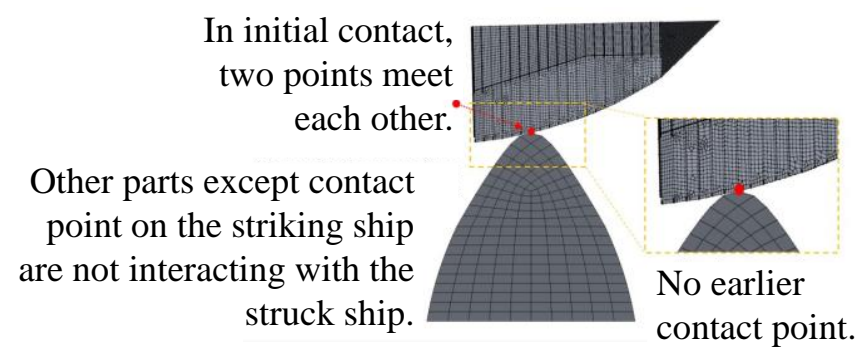

(c)

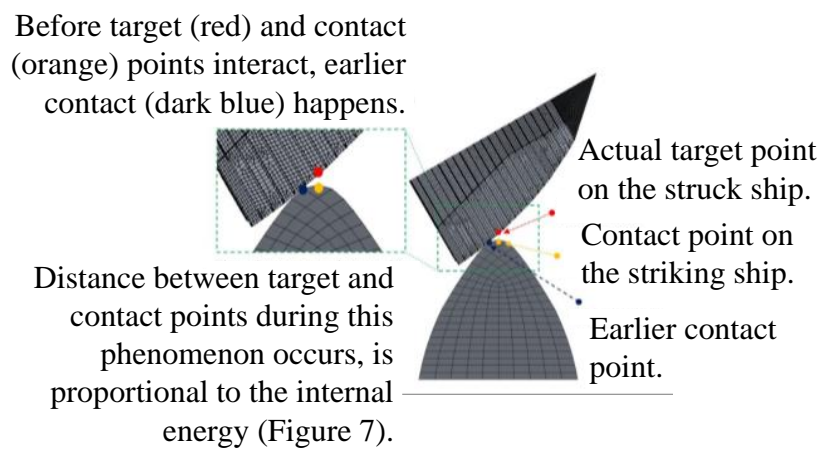

(d)

Figure 6. Comparative illustration of perpendicular and oblique collision: (a) initial situation in perpendicular scenario, (b) initial situation in oblique scenario, (c) situation during initial contact in perpendicular collision, and (d) situation during earlier contact phenomenon occurs in perpendicular collision.

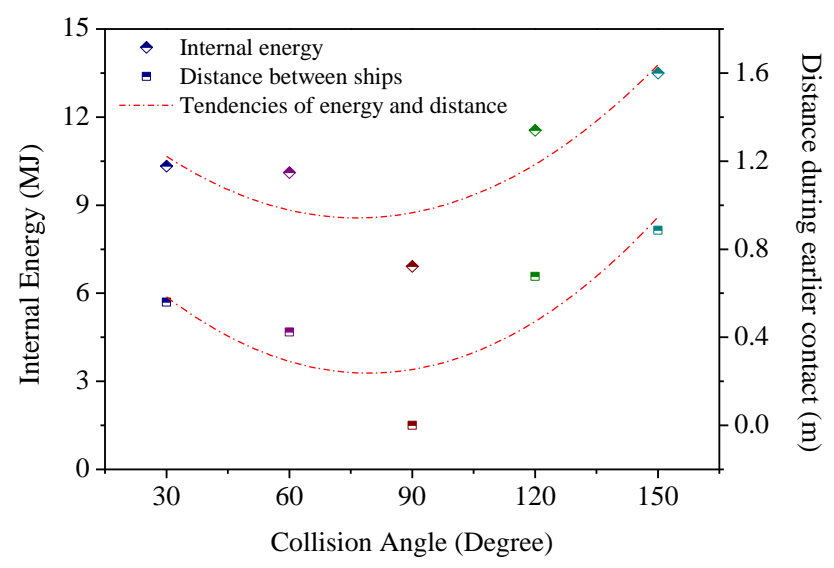

Figure 7. Behaviour of the internal energy and distance between two ships during earlier contact.

This earlier contact phenomenon makes the struck ship experience more deformation, as plastic deformation or even penetration has already begun before initial contact between targets on the striking and struck ships happens, which leads to the occurrence of a greater overall extent of damages. As introduced in the discussion of the empirical formulae for estimating the collision energy, the energy during collision is directly proportional to the damage volume, and we can conclude from this discussion that a certain collision angle range in an oblique collision will lead to a significant 
magnitude of energy. The correlation between distances of the designated points in earlier contact and behaviour of the internal energy is presented in Figure 7 for collision angles $30^{\circ}, 60^{\circ}, 90^{\circ}, 120^{\circ}$, and $150^{\circ}$ with striking 2 and struck ship considered in the analysis.

\section{Extent of Damage}

In addition to the magnitude of the energy, the damage pattern is also recorded in the end collision process. This sub-section will describe the damage behaviour on the outer shell after the collision event. The correlation between energy and damage pattern shows good agreement, as the energy magnitude is directly proportional to the damage on the side structure. The tearing damage of a collision angle of $30^{\circ}$ (Figure 8 ) is found to be the larger than those of the $90^{\circ}$ and $150^{\circ}$ angles during the collision with striking 2 in the upper location. In the perpendicular collision (Figure 9), the side shell experiences almost-symmetrical damage while the side part of the middle and main decks become deformed. The similar form with the oblique collision damage of the $30^{\circ}$ angle is spotted on collision with $\beta=150^{\circ}$ (Figure 10), where the damage on the outer shell is dominant in the longitudinal direction. We can summarise from this result that in an oblique collision, damage on the outer shell is dominated by tearing in the longitudinal direction, while as the collision angle approaches $90^{\circ}$, the damage orientation changes from the longitudinal into the vertical direction. These results also indicate that the factor of the shape of the objects and the structural arrangement in a complicated structure cannot be avoided. As already described in Cartesian coordinate systems, the angles of $30^{\circ}$ and $150^{\circ}$ have the same number of degrees from $90^{\circ}$, but the locations of these angles are on different quadrants, which makes the angles in opposite directions.
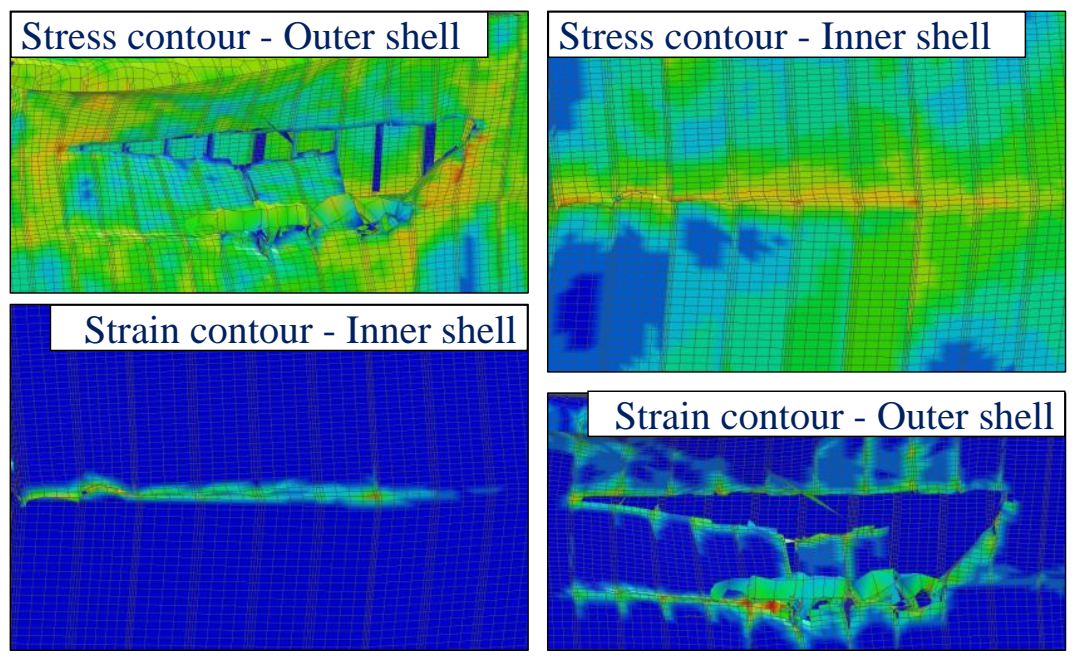

Figure 8. Damage pattern on the double hull components during a collision between the struck ship and striking 2 on oblique scenario $30^{\circ}$. 

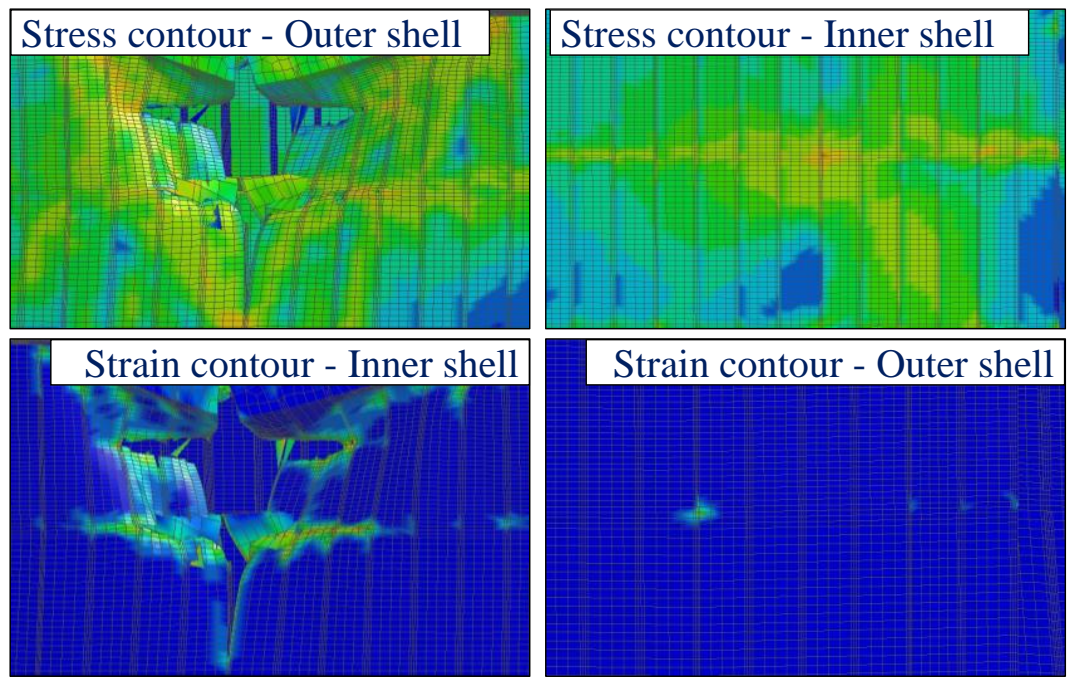

Figure 9. Damage pattern of on the double hull components during a collision between the struck ship and striking 2 on the perpendicular scenario $90^{\circ}$.
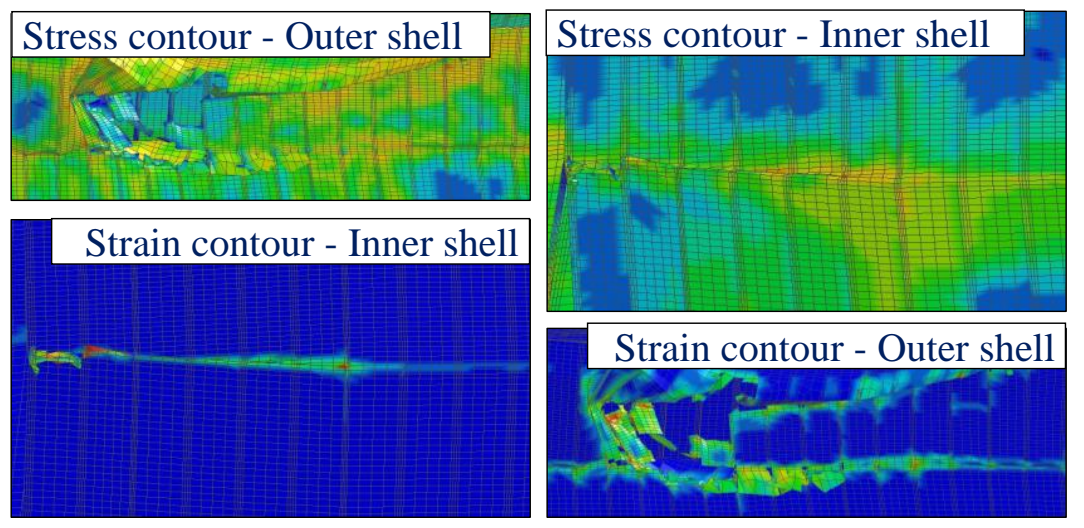

Figure 10. Damage extent on the outer and inner shells of the struck ship vs. striking 2's scenario on $150^{\circ}$.

Despite these facts, the damage on the struck ship is clearly found to be different at these angles. The characteristics of the stress contour on the inner shell are found high along the intersection between the middle deck and inner shell for the oblique collisions at $30^{\circ}$ and $150^{\circ}$. However, the perpendicular collision produces slightly high stress on the small area of the intersection. The behaviour of the plastic strain is observed to be similar to the stress, as the strain is widely distributed along the intersection for the oblique collision. In a collision at $90^{\circ}$, the strain on the inner shell is concluded to be unlikely, which is considered good for cargo safety. 


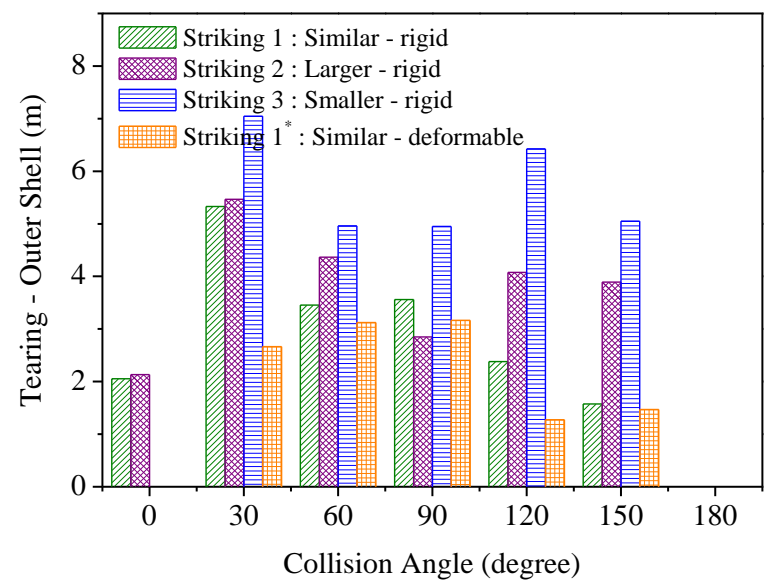

Figure 11. Result of tearing mode on the outer shell of double-side skin structure.

The result of the overall extent of the damage for the collision scenario with the proposed striking ships is also presented in this part. The deformation mode on the double side shell is divided into two parts, namely, tearing on the outer shell and displacement of the inner shell. This classification is considered because the extent of the damage on the double-shell can be varied, including plastic deformation, tearing, folding, and displacement. To focus this discussion, the extent of the damage shall be observed further for tearing and displacement for the outer and inner shells consecutively, as these damage modes dominate the deformation pattern at each location. Tearing (Figure 11) on the outer shell is found to occur after a collision with the smaller ship, which penetrates at a different location than other striking ships. This lower location (Location II in Figure 4) is in the area between the middle and the car decks, and even though this location is penetrated by the smaller ship rather than the upper location, this location already produces greater tearing. We can, therefore, assume that if the lower location collides with the larger ship (e.g., striking 1 and 2), the damage will be immense.

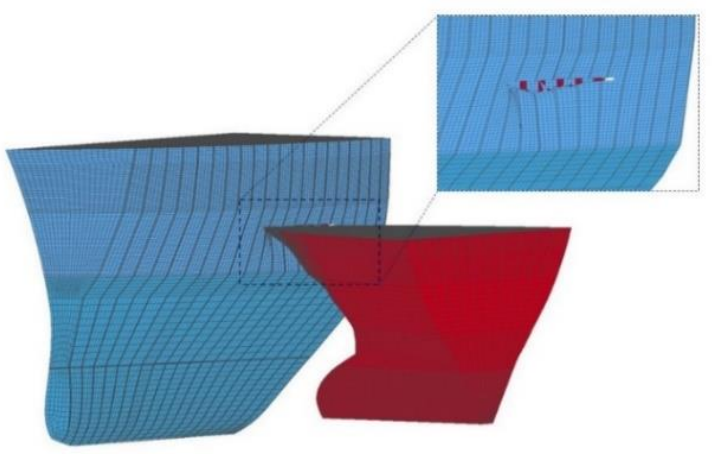

(a)

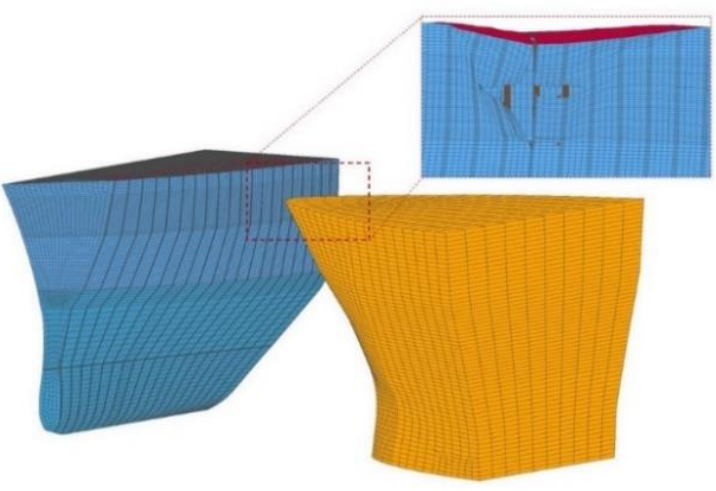

(b)

Figure 12. Influence of striking ship's size to the location of target point: (a) smaller ship, and (b) larger ship. The size directly leads to the difference of deformation mode, pattern, and size during and after the collision process.

However, the collision scenario with the upper part of the larger ship for this location is unlikely to take place, as the tip of the bow from the larger ship cannot penetrate 
the lower location, as the design draft of the striking ship does not allow this scenario to occur. The illustration for the effect of the ship size on the extent of the target location on the struck ship is presented in Figure 12. In this figure, it is explicitly described that the larger striking ship tends to impact the upper structure, and the smaller striking ship penetrates the lower target due to its size. Even though it is impossible for the tip of the bow, this location is still susceptible to penetration by the bulbous bow of a very large striking ship, especially with a blunt bulbous bow, which is very dangerous based on the discussion of the impacted area: the blunt shape can create larger casualties on the target object. For the upper location, striking 2 as the larger ship than the struck ship successfully produces more tearing on the outer shell. This result can be considered relevant as the larger ship is capable of delivering a larger impact, which results in larger casualties, or in this case, more tearing.

In addition to the damage on the outer shell, displacement on the inner shell is discussed, as presented in Figure 13. Displacement is considered for this part as no tearing is found after collision with all striking ships. A large proportion of the energy has been absorbed during the collision with the outer shell. This phenomenon is verified by the major damage observed on the outer shell, while the inner shell experiences minor damage with the farthest displacement spotted approximately $0.60 \mathrm{~m}$ in distance from the initial position. This result also indicates that on the fore-end region, during a collision that occurs as proposed in this work, a safe distance is evidenced to provide good resistance capability in securing the ship cargo on the car deck. Displacement based on the result in Figure 17 is in the range between 0 and $0.60 \mathrm{~m}$, where large displacement is dominated by the collision scenario of striking 1 - similar ship, and striking 2 - larger ship. The smaller ship that contacts the lower location or near the car deck contributes less significantly to the displacement of the inner shell.

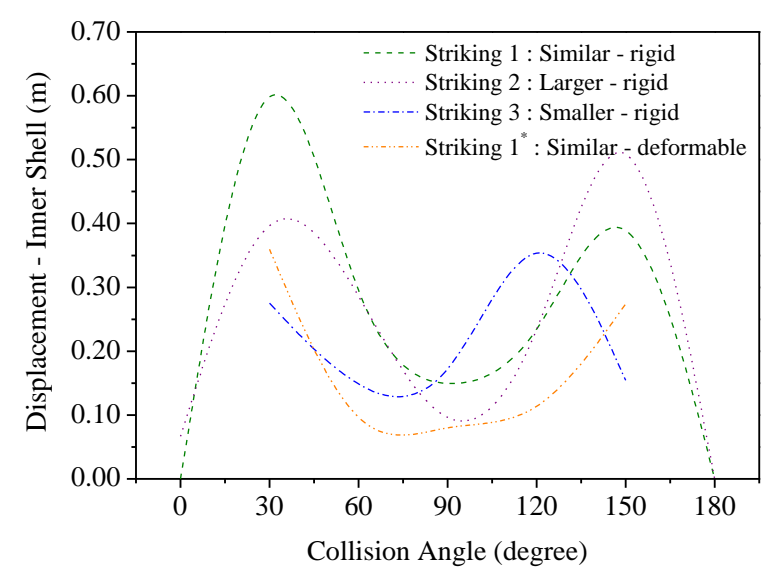

Figure 13. Displacement of the inner shell on the struck ship.

The tendency of this result implies that the contribution of the collision to the displacement distance is more likely produced by an oblique collision than the perpendicular scenario, which is matched with the behaviour of earlier contact, as discussed in a previous part. In the perpendicular collision, contact between the target points is clearly taking place without any other contact of involved objects before these points meet in the moment of initial contact. In an oblique collision, earlier contact is evidenced to lead to earlier deformation (Figure 10). For the same period of time, this scenario shall contribute to a larger damage pattern, or included this discussion is the displacement of the inner shell. 
All proposed cases show a good tendency with irregularity occurring in the collision scenario with striking 3. This phenomenon is evidence that the upper and lower locations (refer to Location II in Figure 8) have different behaviours when encountering a side collision, as striking 3 has impacted a different location than the other striking ships, which have impacted the upper location.

\section{Hull Behaviour based on Collision Types}

Side collision involves two ships and allows the struck ship to be penetrated by the striking ship, producing higher energy magnitude since a crushing force to destroy the structure and create extensive damage on the struck ship is needed. In a side collision, the energy will continue to increase as the penetration of the striking object is deepened. The contact period in this collision type will generally continue since structure parts of the struck ship still exist after penetration has breached the outer shell. The characteristics of the side collision are presented in Figure 14(a). However, the sliding phenomenon that occurs in a certain time period depends on the shape and pattern of the involved objects. The constant, straight, and no-curved body (e.g., the parallel middle body of the side hull) shall make this phenomenon occur longer than during contact on a nonlinear or curved body, as can be found on the foreend region.

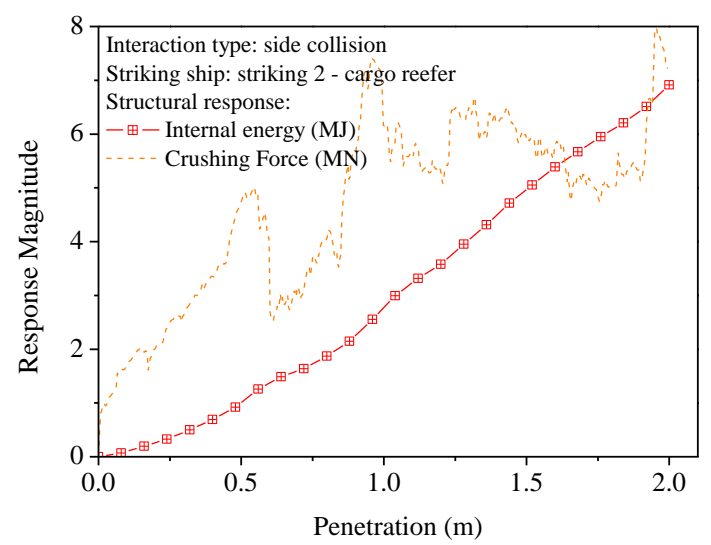

(a)

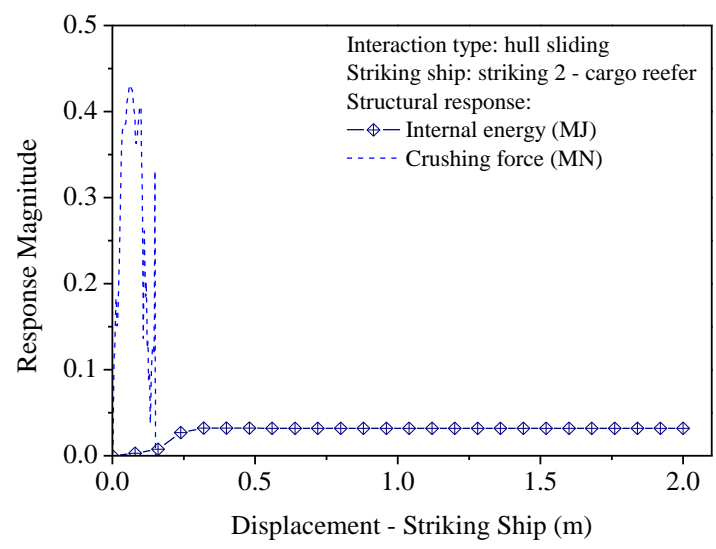

(b)

Figure 14. Behaviour of energy and force on the side collision: (a) in the perpendicular scenario $\left(90^{\circ}\right)$, and (b) collision scenario with angle $0^{\circ}$.

The term penetration cannot be used in this phenomenon (Figure 14(b)) since the penetration on the struck ship is not found at the end of the process. Thus, the contact period became short and under these conditions, the crushing force dropped to zero when the contact is ended. At the same time, the energy magnitude moved constantly (neither rise nor fall), since there is no contact of objects from this point. This situation means that the sliding phenomenon produces only minor damage such as plastic tension on both contacted objects when two deformable entities involved.

\section{CONCLUSION}

The present work has discussed the behaviour of ship structures on the fore-end region against side collision with other ship. A set of collision scenarios represented by different striking ships as indenter and collision angle has been analysed. The calculation was 
successfully carried out by virtual simulation analysis using finite element codes, and discussion of the results is addressed to observation and evaluation of energy and damage during and after the collision process. Several remarkable results and conclusions are summarised in this section. The results of the study show that the energy for side collision tends to be reduced when a collision occurs in the perpendicular position, and the energy rises in an oblique collision scenario. The behaviour of the energy reaches good agreement with the tearing length on the outer shell, which successfully satisfies the behaviour of the absorbed energy by energy formulae in several pioneer works, such as by Minorsky, Woisin, and Zhang.

Based on the deformation mode of the outer hull, the smallest $\left(\beta=0^{\circ}\right)$ and largest $\left(\beta=180^{\circ}\right)$ angles produce different phenomena, the so-called sliding collisions and headto-head. In the sliding collision with angle $0^{\circ}$, the outer hulls of the striking and struck ships glance at each other with penetration unlikely to be found when the striking ship approaches in the same direction as the struck ship. Different results are shown in the head-to-head collision. The striking ship impacts the front part of the fore-end region on the struck ship, instead of the side part as shown in collision ranges from $30^{\circ}$ to $150^{\circ}$. This phenomenon occurs with the assumption that during the collision at $180^{\circ}$, the striking ship comes from the opposite direction to the struck ship with the position of both ships almost in one line, which makes penetration possible. The perspective of the impacted area is considered vital in non-linear and dynamic phenomena such as ship collision. Influence of position, size, shape, and structural arrangement deliver a major effect on structural behaviour with the occurrence of earlier contact phenomena in ship collisions with various angles. Even though significant tearing damage occurs on the outer shell after the collision, the inner shell that is the last protection against a collision with the ship cargo is found to be intact and experiences only minor damage. This tendency, where severe damage is observed on the outer shell and the only displacement occurs on the inner shell, leads to the conclusion that the double hull design on the side structure of the struck ship has satisfyingly provided sufficient resistance capability as energy is absorbed mainly by the outer structural members during the encounter of accidental damage in form of a side collision. This conclusion is derived from the tendency of the energy and deformation mode that even if the struck ship is penetrated by the striking ships, the condition of the inner shell is still conserved with no major damage, i.e., a tearing mode is spotted at the end of the collision.

The current configurations and results can be used as a reference for further analysis of ship collisions. Opportunity to expand assessment on ship collisions is recommended to be conducted in a comparative study on structural behaviour with the collision of the fore-end region that has a curved shape as presented in this work and the middle region that is dominated by the flat shape of its side hull. Involvement of other parts of the striking ship such as a bulbous bow is highly encouraged for consideration in the proposed comparative study.

\section{REFERENCES}

[1] Nguyen TH, Amdahl J, Leira BJ, Garrè L. Understanding ship-grounding events. Marine Structures, 2011; 24: 551-569.

[2] Prabowo AR, Cao B, Bae DM, Bae SY, Zakki AF, Sohn, JM. Structural analysis of the double bottom structure during ship grounding by finite element approach. Latin American Journal of Solids and Structures, 2017; 14: 1-18. 
[3] Prabowo AR, Cho HJ, Lee SG, Bae DM, Sohn JM, Cho JH. Investigation on the structural damage of a double-hull ship, Part II - Grounding impact. Procedia Structural Integrity, 2017; 5: 943-950.

[4] Prabowo AR, Muttaqie T, Sohn JM, Harsritanto BIR. Investigation on structural component behaviours of double bottom arrangement under grounding accidents. Theoretical \& Applied Mechanics Letters, 2019; 9: 50-59.

[5] Ståhlberg K, Goerlandt F, Ehlers S, Kujala P. Impact scenario models for probabilistic risk-based design for ship-ship collision. Marine Structures, 2013; 33: 238-264.

[6] Bae DM, Prabowo AR, Cao B, Sohn JM, Zakki AF, Wang Q. Numerical simulation for the collision between side structure and level ice in event of side impact scenario. Latin American Journal of Solids and Structures, 2016; 13: 2691-2704.

[7] Prabowo AR, Baek SJ, Byeon JH, Bae DM, Cho JH, Sohn JM. Investigation on the structural damage of a double-hull ship, Part I - Ship collision. Procedia Structural Integrity, 2017; 5: 935-942.

[8] Prabowo, AR, Bae DM, Sohn JM, Zakki AF, Cao B, Cho JH. Effects of the rebounding of a striking ship on structural crashworthiness during ship-ship collision. Thin-Walled Structures, 2017; 115: 225-239.

[9] Minorsky VU. An analysis of ship collision with reference to protection of nuclear power ships. Journal of Ship Research, 1958; 3: 1-4

[10] Woisin G. Design against collision. Schiff \& Hafen 1979; 31: 1059-1069.

[11] Zhang S, Villavicencio R, Zhu L, Pedersen PT. Ship collision damage assessment and validation with experiments and numerical simulations. Marine Structures, 2019; 63: 239-256.

[12] Paik JK. Practical techniques for finite element modelling to simulate structural crashworthiness in ship collisions and grounding (Part I: Theory). Ships and Offshore Structures, 2007; 2: 68-80.

[13] Salloomi KN, Sabri LA, Hamad YM, Al-Sumaidae S. Nonlinear buckling analysis of steel cylindrical shell with elliptical cut-out subjected to longitudinal compressive load. International Journal of Automotive and Mechanical Engineering, 2019; 16: 6723-6737.

[14] Jahani M, Behesti H, Heidari-Rarani M. Effects of geometry, triggering and foamfilling on crashworthiness behaviour of a cylindrical composite crash box. International Journal of Automotive and Mechanical Engineering, 2019; 16: 65686587.

[15] Ozguc O, Das PK, Barltrop N. A comparative study on the structural integrity of single and double skin bulk carriers under collision damage. Marine Structures, 2005; 18: 511-547.

[16] Alsos HS, Amdahl J. On the resistance of tanker bottom structures during stranding. Marine Structures, 2007; 20: 218-237.

[17] Törnqvist R. Design of crashworthy ship structures. Lyngby: Technical University of Denmark; 2003.

[18] Rice J, Tracey D. On the ductile enlargement of voids in triaxial stress fields. Journal of Mechanics and Physics of Solids, 1969; 17: 201-217.

[19] Cockcroft MG, Latham DJ. Ductility and the workability of metals. Journal Institute of Metals, 1968; 96: 33-39.

[20] Zhang S. The mechanics of ship collisions. Lyngby: Technical University of Denmark; 1999. 
[21] Alsos HS, Amdahl J. On the resistance to penetration of stiffened plates, Part I Experiments. International Journal of Impact Engineering, 2009; 36: 799-807.

[22] AbuBakar A, Dow RS. Simulation of ship grounding damage using the finite element method. International Journal of Solids and Structures, 2013; 50: 623-636.

[23] Prabowo AR, Bae DM, Sohn JM, Cao B. Energy behavior on side structure in event of ship collision subjected to external parameters. Heliyon, 2016; 2: e00192.

[24] ANSYS. ANSYS LS-DYNA user's guide. Pennsylvania: ANSYS, Inc; 2019.

[25] Prabowo AR, Bae DM, Sohn JM, Zakki A.F. Evaluating the parameter influence in the event of a ship collision based on the finite element method approach. International Journal of Technology, 2016; 4: 592-602.

[26] Bae DM, Prabowo AR, Cao B, Zakki AF, Haryadi GD. Study on collision between two ships using selected parameters in collision simulation. Journal of Marine Science and Application, 2016; 15: 63-72. 